\title{
BACTERIOLOGICAL STUDY OF POST-OPERATIVE WOUND INFECTIONS AND THEIR ANTIBIOGRAMS IN A TERTIARY CARE TEACHING HOSPITAL
}

\author{
Prasada Rao Namburi ${ }^{1}$, Sisira $D^{2}$, Surendra $B V^{3}$ \\ ${ }^{I}$ Assistant Professor, Department of Microbiology, Fathima Institute of Medical Sciences, Ramarajupalli, Kadapa, \\ ${ }^{2}$ Assistant Professor, Department of Microbiology, ${ }^{3}$ Assistant Professor, Department of Physiology, \\ Viswabharathi Medical College, Kurnool, Andhra Pradesh, India.
}

\begin{abstract}
Background: Surgical site infections (SSI) are frequently occurring in postoperative complications. The present study is undertaken to isolate and determine the frequency of distribution of pathogens in post-operative wound infections and the antimicrobial susceptibility pattern of the causative organisms. Methods: This cross-sectional, prospective study was carried out over a period of one year. 250 pus samples from cases of surgical site infections were processed for gram staining, culture, biochemical identification tests, and antimicrobial susceptibility testing. Results: Out of 250 patients of post-operative wound infections, 48 are cultured positive, among which 21 were gram-positive, and 27 were gram-negative. Staphylococcus aureus emerged as the commonest etiological agent 17 (35.42\%) followed by Pseudomonas aeruginosa $14(29.17 \%)$, E.coli $6(12.5 \%)$. Amikacin $(72.9 \%)$ was found to be the most effective antibiotic, and Multidrug resistance was observed with staphylococcus aureus $(79.16 \%)$ and pseudomonas aeruginosa $(83.3 \%)$. Conclusions: Staphylococcus aureus is the commonest etiological agent for Postoperative wound infections. Antibiotic susceptibility pattern of various isolates helps in proper selection of antibiotics and in this study, it was found that Amikacin was the most effective antibiotic against postoperative wound infections.
\end{abstract}

Keywords: Surgical site infections; Post-operative wound infections; Antibiograms.

\section{INTRODUCTION}

Post operative wound infections cause morbidity and mortality in the field of surgery [1-3] wound infections is caused not only by the skin and soft tissue infection after a break in the skin surface, but also as complication of surgery, trauma, bites or diseases causing a break in the mucosal or skin surface

Postoperative wound infections can be caused by two major sources: exogenous and endogenous. The primary infection of postoperative infections creates after surgery and are caused due to patients own oral pathogens and secondary infection is caused from the hospitals, but type of causative microorganisms may differ from hospital to hospital [4].The occurrence of postoperative wound infection rely upon patient's defense system, condition and type of wounds, and also the drugs prescribed to the patients [5].

Postoperative wound infections [6] delays recovery and often increases the length of stay and may produce lasting sequelae and require extra resources for investigations, management, and nursing care. Therefore, its prevention or reduction is relevant to quality patient care [7].

So, the present study was undertaken to isolate and to identify the bacteria causing postoperative wound infection and to determine the antibiogram of the bacterial isolates in patients.

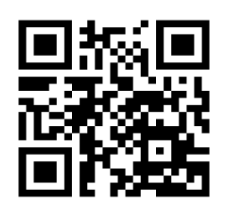

DOI: $10.31878 /$ ijcbr.2020.62.05

eISSN: 2395-0471

pISSN: 2521-0394

\section{MATERIAL AND METHODOLOGY}

Study design: Descriptive cross-sectional prospective study

Ethics: This study was started after prior approval by the Institutional Ethical Committee\& obtained consent from the patients.

Study locus: Fathima Institute of Medical Sciences, Kadapa.

Study period: December 2018 to November 2019

Sample size: 250 postoperatively infected patients

Inclusion criteria: Patients with surgical site infections in surgical wards of General Surgery, Obstetrics \& Gynecology, Orthopedics.

Exclusion criteria: Patients already started on antibiotics, patients unwilling for the study.

Sample collection: 250 random samples were collected from post operative wound infections from patients. Wound swabs were collected in duplicate and pus was collected in sterile container made in to two parts. One for microscopic examination and another for culture. The following investigations were done to isolate the causative agent.

Microscopic examination using Gram's stained smears and cultured on to blood agar, chocolate agar, and MacConkey agar and incubated at $37^{\circ} \mathrm{C}$ for 48 hours before being reported as sterile. Growth on a culture plate was identified by its colony characters $\&$ the battery of standard biochemical tests [8]

The following Bacterial reactions tests done to identify

Correspondence: : Sisira D, Assistant Professor, Department of Microbiology, Viswabharathi Medical College, Kurnool, Andhra Pradesh, India. Email: sisiraunnava@gmail.com 
the microorganisms.

For gram negative bacilli, sugar fermentation, oxidase, catalase, indole, Methyl Red (MR), Voges-Prauskauer (VP), Citrate, Urease, Phenyl-Pyruvicacid (PPA), Hydrogen sulphide (H2S), Triple Sugar Iron (TSI) tests were done

In case of Gram-positive cocci, Coagulase test, Phosphatase test were done

Simultaneously Antimicrobial sensitivity testing was done by Kirby-Baeur disk diffusion method on Mueller Hinton agar as per CLSI guidelines [9] and the antibiotics are coded as Ampicillin (A) $10 \mu \mathrm{g}$; Erythromycin (E) $15 \mu \mathrm{g}$; Amikacin (AK) $30 \mu \mathrm{g}$; Amoxyclav (AC) $30 \mu \mathrm{g}$; Gentamicin 9G) $10 \mu \mathrm{g}$; Cephalothin (Ch) $30 \mu \mathrm{g}$.

\section{RESULTS}

Table 1: Bacteria isolated from pus by direct microscopy (Gram's staining)

\begin{tabular}{ll}
\hline Bacteria were seen & Number \\
\hline Gram-negative bacilli & $21(8.4 \%)$ \\
Gram-positive cocci & $27(10.8 \%)$ \\
\hline
\end{tabular}

Sample size: 250, Bacteria isolated: 48 (19.2\%)

\section{Table 2: Pathogens isolated and their antibiotic sensitivity pattern from postoperative wound infections}

\begin{tabular}{|c|c|c|c|c|c|c|c|}
\hline $\begin{array}{l}\text { Bacteria } \\
\text { isolated }\end{array}$ & $\begin{array}{l}\text { Isolates } \\
(\%)\end{array}$ & $\begin{array}{l}\mathbf{A} \\
\mathbf{S} / \mathbf{R}\end{array}$ & $\begin{array}{l}\mathbf{E} \\
\mathbf{S} / \mathbf{R}\end{array}$ & $\begin{array}{l}\text { AK } \\
\text { S/R }\end{array}$ & $\begin{array}{l}\text { AC } \\
\text { S/R }\end{array}$ & $\begin{array}{l}\mathbf{G} \\
\mathbf{S} / \mathbf{R}\end{array}$ & $\begin{array}{l}\text { Ch } \\
\text { S/R }\end{array}$ \\
\hline $\begin{array}{l}\text { Staphylococcus } \\
\text { aureus }\end{array}$ & $17(35)$ & $15 / 2$ & $13 / 4$ & $12 / 5$ & $13 / 4$ & $10 / 7$ & $78 / 9$ \\
\hline $\begin{array}{l}\text { Coagulase } \\
\text { Negative } \\
\text { Staphylococcus }\end{array}$ & $4(8.3)$ & $2 / 2$ & $1 / 3$ & $3 / 1$ & $1 / 3$ & $2 / 2$ & - \\
\hline $\begin{array}{l}\text { Pseudomonas } \\
\text { aeruginosa }\end{array}$ & $14(29.2)$ & $9 / 5$ & $10 / 4$ & $10 / 4$ & $8 / 6$ & $10 / 4$ & $45 / 9$ \\
\hline $\begin{array}{l}\text { Escherichia } \\
\text { Coli }\end{array}$ & $\begin{array}{l}6 \\
(12.5)\end{array}$ & $2 / 4$ & $3 / 3$ & $5 / 1$ & $5 / 1$ & $4 / 2$ & - \\
\hline klebsiella & $2(4.2)$ & $2 / 0$ & $1 / 1$ & $1 / 1$ & $1 / 1$ & $2 / 0$ & $1 / 1$ \\
\hline $\begin{array}{l}\text { Proteus } \\
\text { vulgaris }\end{array}$ & $3(6.3)$ & $1 / 2$ & $0 / 3$ & $3 / 0$ & $0 / 3$ & $3 / 0$ & $0 / 3$ \\
\hline Citrobacter & $2(4.2)$ & $2 / 0$ & $1 / 1$ & $1 / 1$ & $2 / 0$ & $2 / 0$ & $2 / 0$ \\
\hline
\end{tabular}

Among 17 isolates of Staphylococcus aureus, 15 were sensitive to Ampicillin, 13 sensitive to Erythromycin, 12 sensitive to Amikacin, 13 sensitive to Amoxyclav, 10 sensitive to Gentamicin and 8 sensitive to Cephalothin. 2 were resistant to Ampicillin, 4 resistant to Erythromycin, 5resistant to Amikacin, 4 resistant to Amoxyclav, 7 resistant to Gentamicin \& 9 resistant to Cephalothin (Table 2).

Among 4 isolates of Coagulase Negative Staphylococcus, 02 were sensitive to Ampicillin,01 sensitive to Erythromycin, 03 sensitive to Amikacin, 01 sensitive to Amoxyclav, 02 sensitive to Gentamicin. 2 were resistant to Ampicillin, 3 resistant to
Erythromycin, 1 resistant to Amikacin, 3 resistant to Amoxyclav, 2 resistant to Gentamicin (Table 2).

Among 14 isolates of Pseudomonas aeruginosa, 09weresensitive to Ampicillin, 10 sensitive to Erythromycin, 10 sensitive to Amikacin, 08 sensitive to Amoxyclav, 10 sensitive to Gentamicin and 5 sensitive to Cephalothin. 5 were resistant to Ampicilin, 4 resistant to Erythromycin, 4 resistant to Amikacin, 6 resistant to Amoxyclav, 4 resistant to Gentamicin \& 9 resistant to Cephalothin (Table 2).

Among 06 isolates of Escherichia Coli, 02weresensitive to Ampicillin, 03sensitive to Erythromycin, 05 sensitive to Amikacin, 05 sensitive to Amoxyclav, 04 sensitive to Gentamicin. 4were resistant to Ampicilin, 3 resistant to Erythromycin , 1 resistant to Amikacin , 1 resistant to Amoxyclav, 2 resistant to Gentamicin (Table 2).

Among 02 isolates of klebsiella, 2 were sensitive to Ampicillin,01 sensitive to Erythromycin, 01 sensitive to Amikacin, 01 sensitive to Amoxyclav, 02 sensitive to Gentamicin and 01 sensitive to Cephalothin. 1 resistant to Erythromycin, 1 resistant to Amikacin, 1 resistant to Amoxyclav \& 1 resistant to Cephalothin (Table 2).

Among 03 isolates of Proteus vulgaris, 01was sensitive to Ampicillin,03 sensitive to Amikacin, 03 sensitive to Gentamicin. 2 were resistant to Ampicilin, 3resistant to Erythromycin, 3 resistant to Amoxyclav\& 3 resistant to Cephalothin (Table 2).

Among 02 isolates of Citrobacter, 2 was sensitive to Ampicillin, 1 sensitive to Erythromycin,01 sensitive to Amikacin, 02 sensitive to Amoxyclav, 02 sensitive to Gentamicin and 02 sensitive to Cephalothin. 1 resistant to Erythromycin, 1 resistant to Amikacin. (Table 2).

\section{DISCUSSION}

Post-operative wound infection still remains one of the most important causes of morbidity and is the most common nosocomial infection $[10,11]$ in surgically treated patients.

Our findings were comparable with many other studies. Staphylococcus aureus, a gram-positive coccus, is a major human pathogen \& a predominant cause of SSIs worldwide with a prevalence rate ranging from $4.6 \%$ to $54.4 \%$ [12].

In our study Staphylococcus aureus was the commonest etiological agent $17(35.42 \%)$. In study by B Ananthi et al, similar reports of Staphylococcus aureus being the most common isolate was observed [13].

Infection with Staphylococcus aureus is most likely associated with endogenous source as it is a member of skin \& nasal flora \& also with contamination from environment, surgical instruments or from hands of health care workers $[14,15]$.

Gram positive organisms were relatively more sensitive to the antibiotics tested than gram negative organisms. Gram positive organisms were sensitive to Ampicillin (80.95\%), Amikacin (71.43\%), Erythromycin and Amoxyclov (66.6\% each), Gentamicin (57.15\%) and gram negative organisms were sensitive to Gentamicin (77.77\%), Amikacin (74.10\%), Cephalothin (64\%), Amoxyclav 
(59.25\%) and Ampicilin (40.75\%).

Multi drug resistance was observed with staphylococcus aureus $(79.16 \%)$ and Pseudomonas aeroginosa (83.3\%).Oncheet al [16] also showed the emergence of resistance strains.

Present study revealed that Amikacin showed highest sensitivity (72.9\%), followed by Gentamicin (68.75\%), Amoxyclav (62.5\%) and Ciproflaxacin (45.25\%) In all the samples both gram positive and gram-negative organisms tested. Pseudomonas aeroginosa which showed $83.3 \%$ multiple drug resistance, showed 64\% sensitivity to first generation cephalosporins. Jamali AR [17] observed that $80 \%$ of the culture organisms were multiple drug resistant strains as compared to $20 \%$ sensitive to the first generation cephalosporins .

\section{CONCLUSION}

Staphylococcus aureus is the commonest etiological agent for Postoperative wound infections. Antibiotic susceptibility pattern of various isolates help in proper selection of antibiotics and in this study it was found that Amikacin was the most effective antibiotic against Postoperative wound infections and Multi drug resistance was observed with Staphylococcus aureus and Pseudomonas aeruginosa.

Clinical implications: The study suggests that although surgical site infections cannot be completely eliminated, a reduction in the infection rate to a minimal level could have significant benefits, by reducing postoperative morbidity and mortality, and wastage of health care resources.

Acknowledgement: The author wishes to thank Dr. N Mary Hemeliamma, Professor \& HOD, Department of Microbiology for her valuable suggestion \& technicians of Microbiology lab, for laboratory help.

\section{Conflict of interest : Nil}

Source of funding : Nil

\section{REFERENCES}

[1] Anguzu JR, Olila D. Drug sensitivity patterns of bacterial isolates from septic post- operative wounds in a regional referral hospital in Uganda. African Journal of Health Sciences. 2007;7:14854

[2] Raza MS, Chander A, Ranabhat A. Antimicrobial susceptibility patterns of the bacterial isolates in post- operative wound infections in a tertiary care hospital, Kathmandu, Nepal. Open Journal of Medical Microbiology. 2013; 3:159-63

[3] Mengesha RE, Kasa BG, Saravanan M, Berhe DF, Wasihun AG. Aerobic bacteria in post surgical wound infections and pattern of their antimicrobial susceptibility in adyer Teaching and Referral hospital, Mekelle, Ethiopia. BMC Research Notes. 2014;7:575-80

[4] Dessalegn L, Shimells T, Tadesse E, Selassie SG. Aerobic bacterial isolates from post- surgical wound and their antimicrobial susceptibility pattern: a hospital based cross-sectional study. Journal of Medical Research. 2014; 3:18-23
[5] Amrita S, Sheetal R, Narendra N. Aerobic Microorganisms in post operative wound infections and their antimicrobial susceptibility pattern. Journal of Clinical and Diagnostic Research. 2010; 4:3392-6

[6] Edmiston CE, Seabrook GR, Johnson CP, Paulson DS, Beausoleil CM. Comparative of a new and innovative 2 percent chlorhexidine gluconate-impregnated cloth with 4 percent Chlorhexidine gluconate as topical antiseptic for preparation of skin prior to surgery. Am J Infect Control. 2006; 35(2): 89-96

[7] Haley RW, Culver DH, Morgan WM, Emori TG, Munn VP, Hooten TM. Identifying patients at high risk of surgical wound infection: a simple multivariate index of patient's susceptibility and wound contamination. Am J Epidemiol. $1985 ; 121: 206-15$

[8] Forbes BA, Sahm DF, Weissfeld AS. Bailey and Scott's Diagnostic Microbiology. 10th ed. St. Louis, Misssouri, USA: Mosby Inc; 1998

[9] CLSI: Performance Standards for Antimicrobial Susceptibility Testing; Twentieth Informational Supplement CLSI Document M100-S20. Wayne, PA: Clinical and Laboratory Standards Institute; 2010

[10] Suljagić V, Jevtic M, Djordjevic B, Jovelic A. Surgical site infections in a tertiary health care center: Prospective cohort study. Surg Today 2010;40:763-71

[11] Desa LA, Sathe MJ. Factors influencing wound infection (a prospective study of 280 cases). J Postgrad Med. 1984;30:231-6

[12] Chakarborty SP, Mahapatra SK, Bal M, Roy S. Isolation and identification of vancomycin resistant Staphylococcus aureus from postoperative pus sample. Al Ameen J Med Sci. 2011;4(2):152-68

[13] Ananthi B, Ramakumar M, Kalpanadevi V, Abigail RS, Karthiga L, Victor HK, et al. Aerobic bacteriological profile and antimicrobial susceptibility pattern in post-operative wound infections. Int J Medi Sci Clin Inven. 2017;4 (2):2702-6

[14] Isibor OJ, Oseni A, Eyaufe A. Incidence of aerobic bacteria and Candida albicans in postoperative wound infections. Afr J microbial Res. 2008;2:28891

[15] Lilani SP, Jangale N, Chowdhary A, Daver GB. Surgical site infection in clean and cleancontaminated cases. Indian J Med Microbiol. 2005;23:249-52

[16] Onche, O. Adedeji, Microbiology of post operative surgery wound infection in implant surgery. Nigerian journal of Surgical research, 2004;6(1-2): 37-40.

[17] Jamali AR. post operative wound infections in orthopedic surgery, J. Coll Physicians Surg pak 2001;11(12):747-9 